\title{
COVID-19: Care for Infants and Children \& Competition for Resources
}

Darby O'Donnell, JD and the AfPA Governmental Affairs Team Alliance for Patient Access (AfPA)

The Alliance for Patient Access (allianceforpatientaccess.org), founded in 2006, is a national network of physicians dedicated to ensuring patient access to approved therapies and appropriate clinical care. AfPA accomplishes this mission by recruiting, training and mobilizing policy-minded physicians to be effective advocates for patient access. AfPA is organized as a non-profit 501 (c) (4) corporation and headed by an independent board of directors. Its physician leadership is supported by policy advocacy management and public affairs consultants. In 2012, AfPA established the Institute for Patient Access (IFPA), a related 501(c) (3) non-profit corporation. In keeping with its mission to promote a better understanding of the benefits of the physician-patient relationship in the provision of quality healthcare, IfPA sponsors policy research and educational programming.

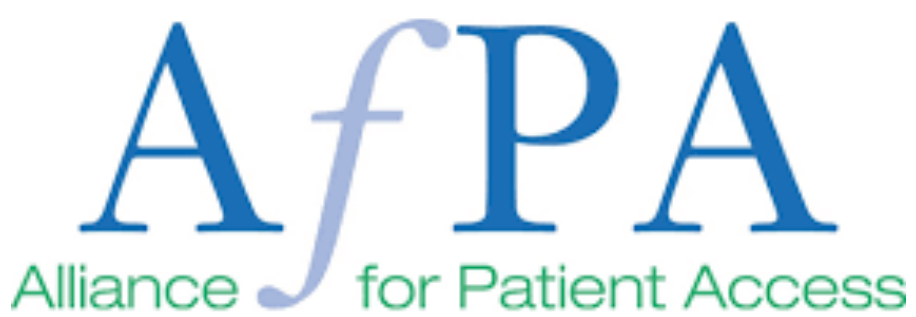

Congress passed the Coronavirus Aid, Relief, and Economic Security (CARES) Act - a bipartisan, $\$ 2$ trillion COVID-19 relief package for U.S. families, physicians, health care providers, job seekers, employers, and small business owners alike - at the end of March.

The aim was both economic and public health-related in light of the damage already done and to come from the coronavirus pandemic. Despite its magnitude - notably the largest rescue package in U.S. history - not every patient or health care provider was an immediate beneficiary of the congressional relief funds.

\section{Physicians, Family Practices and Children's Hospitals}

Those who treat children and infants as their primary source of income - physicians, family practices and children's hospitals - fell largely just beyond the scope of CARES Act relief funding, round one (so-called CARES tranche 1) because those early funds were geared towards Medicare beneficiaries and distributed based on Medicare revenues.

As the Children's Hospital Association (CHA) explained it, "Children's hospitals were not supported from this distribution as they do not serve Medicare patients (65 years and older) yet are among the highest Medicaid providers in the country, with Medicaid accounting for over $50 \%$ of their patients." (1)

\section{'It is critical that frontline physicians} who may not participate in Medicare feefor-service, in whole or in part, including obstetrician-gynecologists, pediatricians, and family physicians, have the resources they need to continue providing essential health care to patients amid the pandemic and in the months to come," they wrote."

The New York Times acknowledged in a recent article pediatric practices have the most to lose. For starters, pediatricians are among the lowest paid of the medical specialties. And they could be the "hardest hit" of the health practice areas; since they "don't generally treat Medicare patients, they were not compensated for the decline in visits as parents chose not to take their children to the doctor and skipped their regular checkups." (2)

In late April, the American Academy of Family Physicians, the American Academy of Pediatrics, and the American College of Obstetricians and Gynecologists joined forces to write to the U.S. Department of Health and Human Services Secretary Alex Azar asking him to address non-Medicare patients and their providers.

"It is critical that frontline physicians who may not participate in Medicare fee-for-service, in whole or in part, including obstetrician-gynecologists, pediatricians, and family physicians, have the resources they need to continue providing essential health care to patients amid the pandemic and in the months to come," they wrote. (3)

\section{CARES Act Funding, Round 2}

On April 24th, about two weeks after the Department of Health and Human Services (HHS) released a first batch of funding to hospitals and physicians, a second tranche of the CARES Act COVID-19 relief funding was released for providers to include those left out of the previous allocation. HHS's action was lauded by

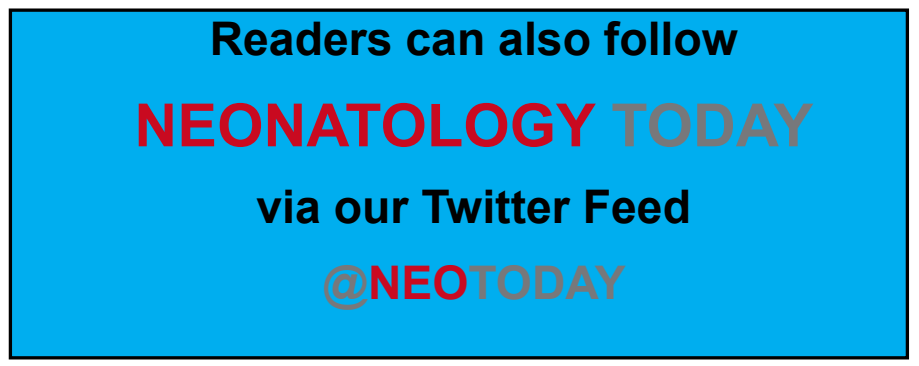


many as relief reached a broader range of health care providers, with less restrictions to their relief based on the age or insurance enrollment of their patients.

The pediatric community was quick to respond.

CHA noted that while "children's hospitals represent only $2 \%$ of all the nation's hospitals, they serve $25 \%$ of the U.S. population," and in the midst of COVID-19 "children's hospitals deferred pediatric care and experienced significant drops in volumes related to local and federal stay-at-home guidance." CHA claimed that their affiliated hospitals' patient care revenues fell roughly $40-50 \%$, which equated to an operating loss in excess of $\$ 2$ billion each month across the nation's children's hospitals. The late allocation of CARES Act funding had "mitigated only a fraction" of the damage to the operating costs of children's hospitals across the country.

Meanwhile, the coalition which included the American Academy of Pediatrics and the American Academy of Family Physicians raised the consequences of pediatric and family-centered practices losing income and closing their doors without "urgently needed financial relief" via HHS. One critical concern with these physicians shuttering their doors would be lose of access to infant and childhood immunizations - which would be put off or less frequently administered, resulting potentially in future outbreaks of vaccinepreventable diseases and creating an uphill battle for families and public schools that require these immunizations.

\section{"One critical concern with these}

physicians shuttering their doors would be lose of access to infant and childhood immunizations - which would be put

off or less frequently administered, resulting potentially in future outbreaks of vaccine-preventable diseases and creating an uphill battle for families and public schools that require these immunizations."

Hospitals and family-centered care facilities are navigating new

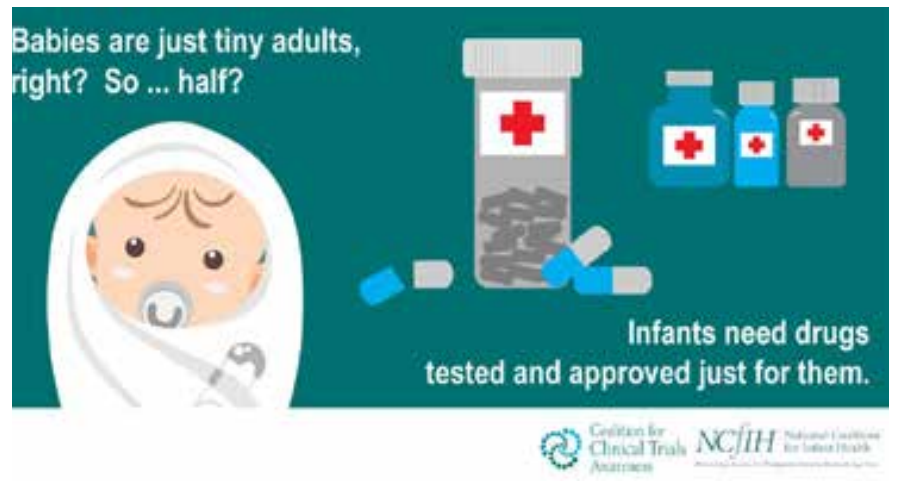

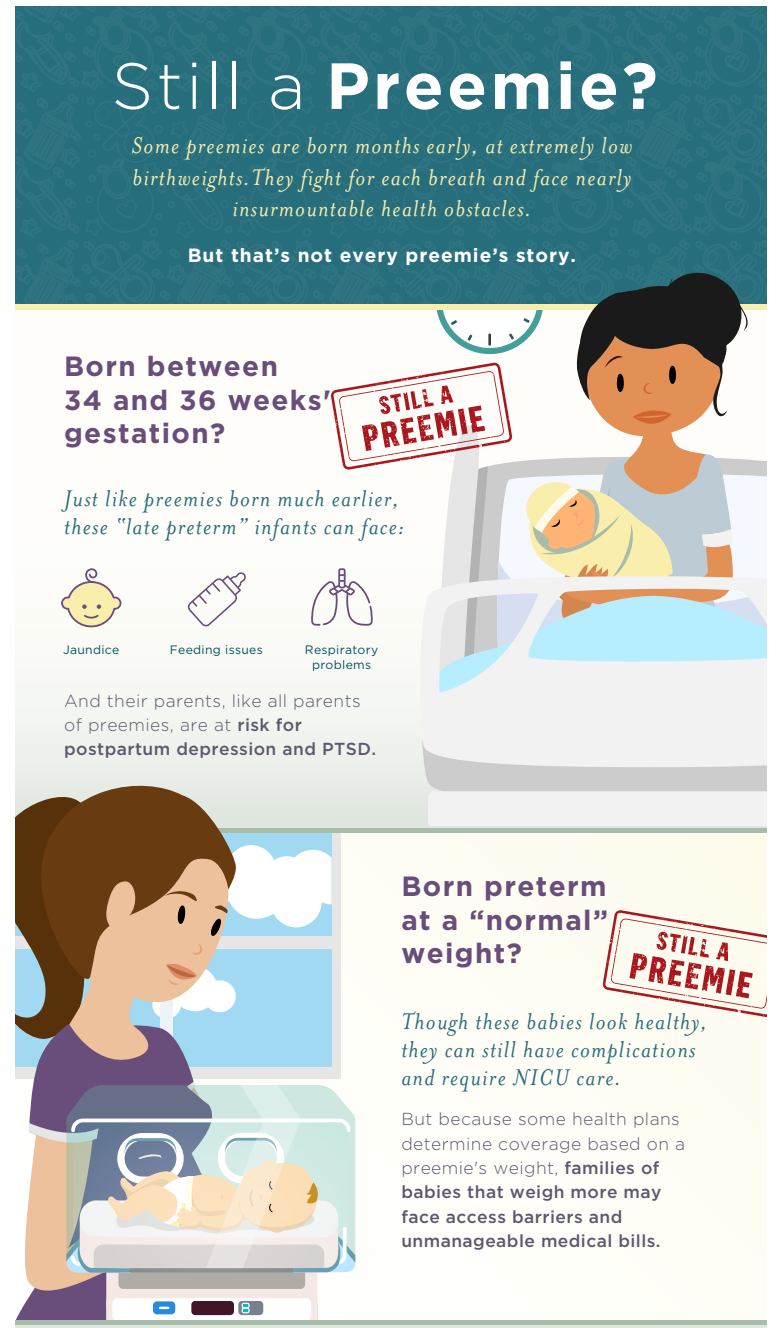

Born preterm but not admitted to the NICU?

Even if preterm babies don't require NICU care, they can still face health challenges. Those challenges can extend through childhood, adolescence and even into adulthood.
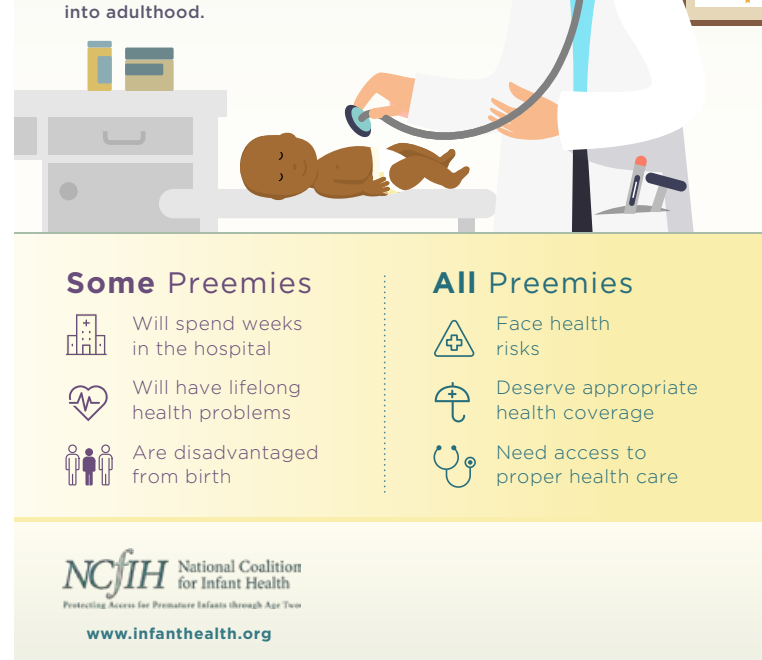
waters when it comes to pediatric care. With employee furloughs, reduced outpatient and inpatient services, previously bustling pediatric units and clinics are now ghost towns. The emotional impact to nurses, staff, and other providers, when not seeing their patients, cannot be overstated.

"As the pandemic ramps down and stay-athome orders expire, continued federal relief may be forthcoming. Access and support for pediatric care must be included."

As the pandemic ramps down and stay-at-home orders expire, continued federal relief may be forthcoming. Access and support for pediatric care must be included.

\section{References:}

1. https://www.childrenshospitals.org/Newsroom/Press-Releases/2020/Childrens-Hospitals-Welcome-Essential-COVID19Relief-from-HHS-Allocation

2. https://www.nytimes.com/2020/05/05/health/coronavirus-primary-care-doctor.html

3. https://www.aafp.org/dam/AAFP/documents/advocacy/payment/medicare/LT-HHS-COVIDReliefFunds-042820.pdf

The author has not indicated any disclosures.

NT

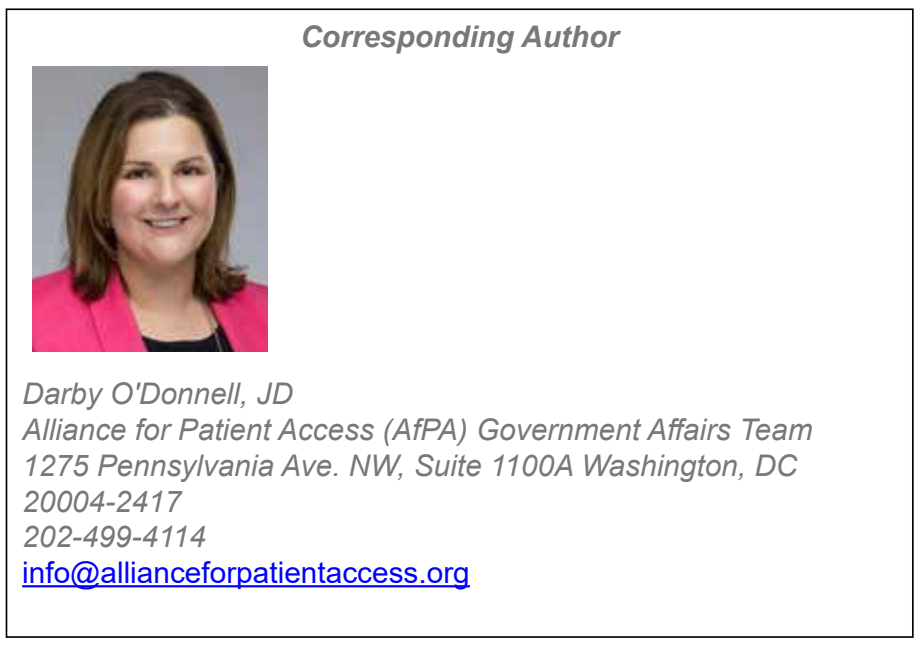

$$
\begin{aligned}
& \text { Readers can also follow } \\
& \text { NEONATOLOGY } \\
& \text { via our Twitter Feed } \\
& \text { @NEOTO }
\end{aligned}
$$
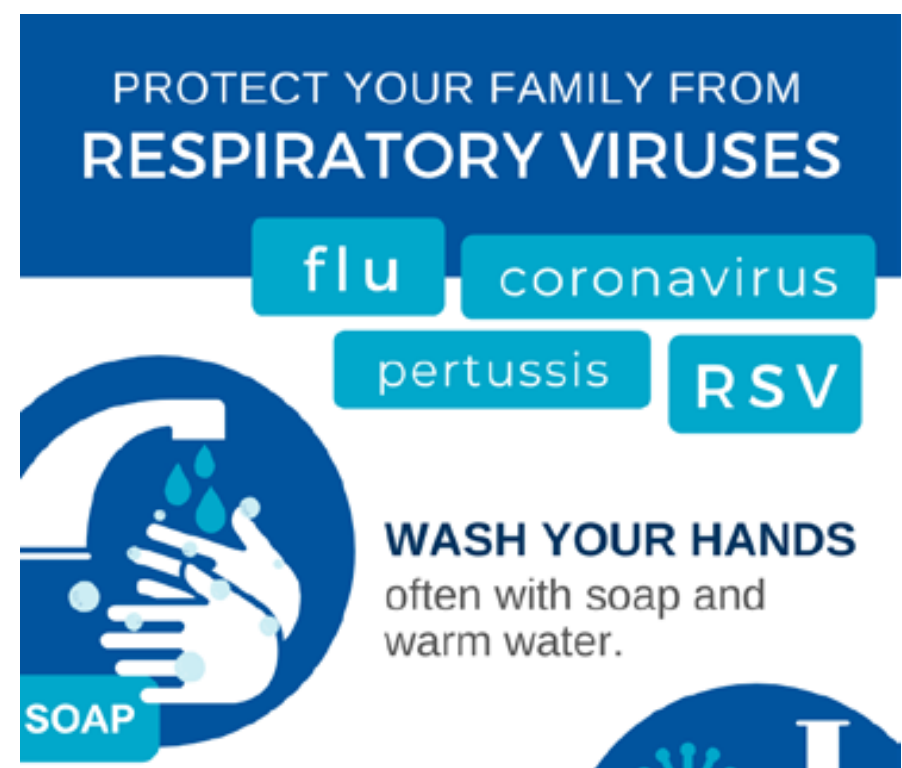

WASH YOUR HANDS often with soap and warm water.

\section{GET VACCINATED}

for flu and pertussis. Ask about protective injections for RSV.

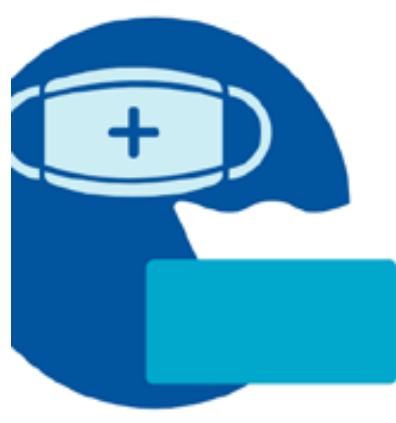

COVER COUGHS AND SNEEZES. Sneeze and cough into your elbow.

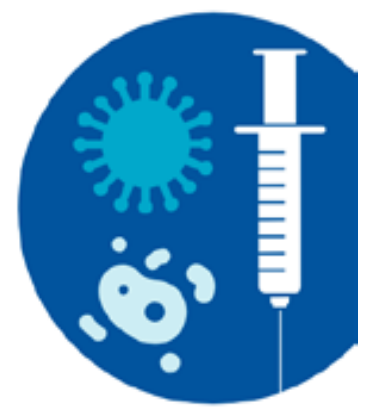

\section{USE AN}

ALCOHOL-BASED HAND SANITIZER.

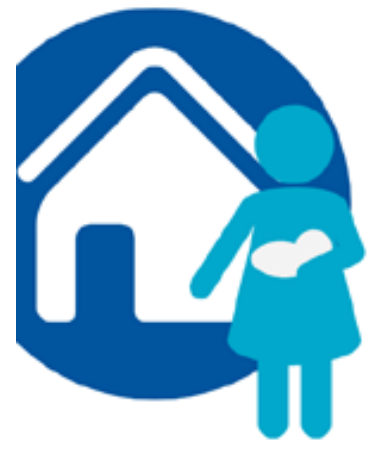

www.nationalperinatal.org

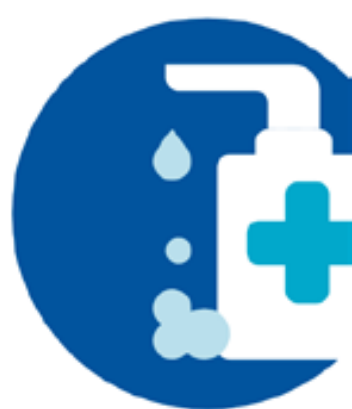

STAY AWAY FROM SICK PEOPLE

Avoid crowds.

Protect vulnerable babies and children.

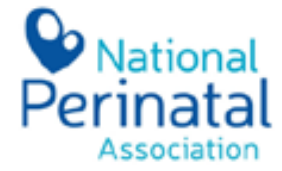

